\title{
Emotions in economic action and interaction
}

\author{
Nina Bandelj
}

Published online: 25 April 2009

(C) The Author(s) 2009. This article is published with open access at Springerlink.com

\begin{abstract}
How do emotions influence economic action? Current literature recognizes the importance of emotions for economy because they either help individuals perform economic roles through emotion management or enhancement of emotional intelligence, or because they aid rationality through their influence on preference formation. All these strands of research investigate the link between emotions and economy from an atomistic/individualistic perspective. I argue for a different approach, one that adopts a relational perspective, focuses on emotional embeddedness and examines how emotions matter in economic interactions. Emotional embeddedness research starts with a premise that emotions result from and are influenced by interactions between economic actors during the economic process where emotional currents and their visceral and physical manifestations come to the fore. This increases the uncertainty in economic transactions and complicates the given means-ends logic of rational economic decision making, yielding economic action principles different from utility maximization. I propose two types of such creative economic action in this paper: improvisation and situational adaptation. Improvisation characterizes situations where ends (goals) and means are unclear at the beginning of a transaction process and get articulated as a consequence of emotional embeddedness experienced during a process. Situational adaptation characterizes situations in which means or ends of action change because of interaction-induced emotions that prompt actors to choose new means/ends. The article concludes with a call for empirical research that explicates further the influence of emotions not merely for rational economic action but also creative economic interactions.
\end{abstract}

\footnotetext{
N. Bandelj $(\bowtie)$

Department of Sociology, University of California, Irvine, CA 92697, USA

e-mail: nbandelj@uci.edu
} 
Since Enlightenment, Western societies have considered emotions and emotionality as the antithesis of reason and rationality (Harding and Pribram 2004). In particular, economic analysts interested in rational economic behavior have largely ignored the role of emotions (Elster 1998), or at best treated them as a residual category, as noise that is captured by the error term in the utility function. And while economic sociologists have examined a variety of social forces that influence economic processes, including networks, institutions, politics, and culture, they too have paid little attention to the role of emotions.

Recently, however, considerations of emotions and emotionality have returned to the analyses of economic processes. The most prominent among the economists, Robert Frank (1987, 1998), investigates the strategic role of emotions. Economic sociologist Viviana Zelizer (2000, 2003, 2005) has forcefully argued against the commonly assumed separation of emotion-infused intimate relations and economic rationality into two "hostile worlds." Paul DiMaggio (2002) has made a call for "endogenizing animal spirits" in economic analyses. Jocelyn Pixely (1999, 2002a, 2002b, 2004) and Jean-Pierre Hassoun (2005) have written on emotions and finance. In one of the rare reviews on the topic, Mabel Berezin (2005) in her chapter on "Emotions and the Economy" for the Handbook of Economic Sociology, made a call for more research by economic sociologists into the link between emotions and economic action.

The purpose of this article is to respond to this call and to outline the ways emotions influence economic action, by surveying the existing research and proposing a novel direction of inquiry. I argue that most current literature that recognizes the importance of emotions for the economy adopts an atomistic perspective because it focuses on how emotions shape an individual's economic preferences or behaviors. What remains largely unexamined is the role of emotions in economic interactions between actors. Indeed, in the field of economic sociology atomistic approaches have been heavily criticized ever since Mark Granovetter (1985) famously argued that economic action is crucially influenced by networks of social relations in which actors are embedded. Following this line of inquiry, I propose that we pay attention to emotional embeddedness. That is, I urge researchers investigating the social foundations of the economy to recognize that emotions influence economic action not only because they shape an individual's utility function or economic role performance, but also that emotions matter because they result from, and are influenced by, interactions that an individual has with other social actors during economic processes. Moreover, once we adopt this interactionist stance, we need to reconsider the extent to which economic action can be judged as rational. Admittedly, from the individual actor's viewpoint, emotions can very well be (and are) considered as a heuristic aiding rational economic behavior. However, during economic interactions emotional reactions of all the interacting persons, with their immediate, in situ, visceral and physical manifestations, come to the fore as the interaction is on-going. Such emotional undercurrents and manifestations likely complicate the set means-ends rational logic of any individual's economic decision making and give rise to economic action principles different from utility maximization. I propose two such creative action types in this article, improvisa- 
tion and situational adaptation, and outline the conditions when they are more or less likely to occur. ${ }^{1}$

In the next section, I review the existing approaches on the role of emotions in the economy, including contributions of the emotion management perspective, emotional intelligence literature, and the work that considers emotions as heuristics for rational action. The second part of the article focuses on the role of emotions in economic interaction to present the emotional embeddedness perspective, and elaborates the consequences this approach has for the understanding of economic action as rational, means-ends, action.

\section{Emotions and the economy: focus on the individual}

Most of the existing work on the intersections between emotions and economy adopts a viewpoint of an individual and/or focuses on the self in economic situations. This work includes research on: a) emotion management, b) emotional intelligence, and c) emotions as heuristics aiding economic rationality. I briefly review each of these bodies of work in turn.

\section{Emotion management in occupational roles}

Following dramaturgical theories, one of the most prominent sociological perspectives that highlight the importance of emotions for economic life is the emotion management approach developed by Arlie Hochschild. Hochschild argued that emotions have an irreducible social component; they are governed by social rules and are managed. That is, people try "to change in degree or quality an emotion or feeling" (1979: 561), following cultural scripts that define emotion rules. We evoke, shape, or suppress feelings in line with what we consider appropriate to a particular situation or a particular social role.

How does emotion management relate to economic action? Hochschild developed her ideas based on a study of flight attendants and their emotion work, published in a book entitled The Managed Heart (1983). The author underscored that service workers are trained to express particular emotional reactions as part of their job, so that managing emotions becomes work. For instance, she noted that flight attendant trainees were constantly reminded that their own job security and the company's profit rode on a smiling face (p. 104). Much other work followed this line of research, by investigating how occupational roles that people enact require emotion

\footnotetext{
${ }^{1}$ Throughout the article, I follow Max Weber (1978) and treat economic action as social action since in economic exchanges actors orient behavior to each other and attempt to make sense of each other's actions, as in any other social situation. Adopting this view, I do not try to make a claim that emotions are particularly relevant for economic action but assume that they matter for economic action just as they matter for other kinds of social actions because "any emotional state pushes humans to behave in a particular way" (Turner and Stets 2006: 47). In fact, my aim is to spell out how emotions influence economic actions, by paying particular attention to the role of emotions in economic interactions. Certainly, emotions matter in conjunction with other social forces (e.g., power, culture, institutions, or networks) but I bracket these other influences in this essay.
} 
work. For instance, Jennifer Pierce (1996) studied women lawyers and focused on the aggressive "rambo litigator" style that women have to adopt to be considered serious lawyers. Recently, Bolton and Boyd (2003), using comparable data to those of Hochschild, found that airline cabin crew attendants are skillful emotion managers, not only playing out the emotion rules set by their organizations, but able to juggle and synthesize different types of emotion work, depending on context and their individual motivations.

Hence, from the emotion management perspective, emotions matter for economic action because they are part-and-parcel of occupational (economic) role performance. The focus is on managing emotional reactions and expressions to feel and manifest as closely as possible those emotions that one is supposed to have (or not have) in any particular economic setting. As such, Hochschild's contribution clearly underscores that emotions are not separate from but an integral part of any economic and business situation. While we may indeed observe a lack of overt emotional expressions in some economic settings, we should understand these occurrences through Hochschild's lens of emotion rules. For instance, a wide-spread idea that accountants are emotionless and "objective" does not exemplify that, naturally, emotions and the economy are two separate spheres. Rather, it is evidence for the fact that performing the economic role of an accountant is guided by emotion rules whereby socially appropriate behavior means suppression of emotional expressions.

In its emphasis on the importance of culture in shaping how individuals experience and express - perform-emotions, Hochschild follows the work of Erving Goffman, the pioneer of the dramaturgical perspective. Nevertheless, Hochschild develops a dramaturgy different from Goffman's. As she states, "emotion managers" described by Goffman can be likened to actors who go about their roles in the English theater tradition, where most energy is directed to the outward performance of roles (Hochschild 1979). On the other hand, Hochschild's emotion management perspective is focused on the inward processes, or "deep acting," and can be best compared to the acting theory based on the Stanislavsky method, which proposes that actors use "memories and feelings in such a way as to elicit the corresponding expressions" (1979: 558). That is, while Goffman's dramaturgy emphasizes the display of emotional expressions suitable to roles and situations, deep acting dramaturgy underscores that actors, while portraying emotion on the surface in some situations, in most other instances really try to alter their genuine emotional states, and feel the emotions they are supposed to feel in a particular role and a particular situation. As such, deep acting focuses strongly on the self, and less on the interactions that the self has with others which is more obvious in Goffman's (1967) work on interaction order.

\section{Emotional intelligence and job performance}

Another body of work that examines emotions in the economic sphere with a focus on individuals' behavior is recent research by business scholars and organizational psychologists on, so called, emotional intelligence. The notion of emotional intelligence has become very popular in corporate America over the last fifteen years. As Cherniss (2000: 2) reports, "when the Harvard Business Review published an article on the topic, it attracted a higher percentage of readers than any other 
article published in that periodical in the last 40 years. When the CEO of Johnson \& Johnson read that article, he was so impressed that he had copies sent out to the 400 top executives in the company worldwide."

Although others have written on the topic before, Salovey and Mayer (1990) are credited as the first to define the term emotional intelligence as "a form of social intelligence that involves the ability to monitor one's own and others' feelings and emotions, to discriminate among them, and to use this information to guide one's thinking and action" (p. 187). We can note that the concept of emotional intelligence is close to the notion of emotion management, and the two perspectives have much in common. There is little cross-referencing, however, which may be due to the (overly) psychological focus of the emotional intelligence research, largely ignoring that it is socially defined emotion rules that guide much of the capacity of individuals to manage emotions, as sociologists are quick to emphasize.

The notion of emotional intelligence is pertinent to our discussion of emotions and economy because one of the key questions in this research is how emotional intelligence relates to organizational performance. Many organizational psychologists hold that IQ is not a very good predictor of job performance (Hunter and Hunter 1984, Snarey and Valiant 1985, Sternberg 1995) and EQ-emotional quotient, capturing social and emotional abilities of individuals, is considered a better gauge of potential professional success (Boyatzis et al. 1995; Cherniss 2000).

The literature on emotional intelligence (for a review see Bar-On and Parker 2000) clearly shows that the contemporary Western corporate world explicitly recognizes emotional dimensions as important to successful job performance. Therefore, in the practical business world emotions and rationality are not as separate as they are in most of the economic theory (Elster 1998). ${ }^{2}$ However, the focus in this business research on emotional intelligence is on an individual and on how, practically, development of emotional competencies of managers contributes to organizational efficiency. Consultants to firms and educators in management programs using this literature encourage managers to learn more about how to hone their competencies, learn to manage their emotions and understand the emotions of others in their work environments in order to be more effective as business actors.

Emotions as heuristic for rational economic action

A third strand of research on emotions and economy focuses on how emotions aid economic decision-making. Jocelyn Pixley (2000) argues that finance organizations routinely use emotions in formulating expectations. She states that "emotions are prevalent all the time" and "necessarily play some part in actually fostering 'rational' decision-making in finance organizations" (2000: 42) because they enable economic actors to formulate expectations, and hence make rational decisions.

Indeed, for any particular decision, the number of goals that is logically possible is virtually unlimited, and the number of possible strategies to reach these goals is orders of magnitude larger. Moreover, the number of consequences of any one strategy is enormous, so that unless some drastic pre-selection happens, the number of things to consider is so vast and the action problem is so complex that no action

\footnotetext{
2 The exception is the work of economist Robert Frank, which I review below.
} 
would result. As Matthews and Wells (1994) point out, emotions serve as one of the chief mechanisms to constrain and direct our attention, and hence frame our decisions. Emotions define what shall be considered as relevant for any particular action problem. In addition, during the process of selecting optimal means for desired goals, emotions help us narrow down the range of plausible alternatives and help us rank these alternatives. In all these ways, emotions are very important to rational economic action.

Therefore, it is easy to see that emotions can be incorporated into the rational action model. Specifically, emotions influence what the goals of economic action should be (e.g., may be money or happiness), and they influence how we order our preferences to help achieve our goals (e.g., we can evaluate strategies based on analytical considerations of costs and benefits, or we pick something over another thing based on the level of our emotional attachment to it). In brief, even if our goal is happiness and not profit, we can still go rationally about achieving this goal. ${ }^{3}$ That is, the procedural logic that defines something to be rational-the means-ends schema, is retained. Procedurally, we decide on our goals (ends) and then select the most optimal means to reach them. Hence, it doesn't really matter what those means/ ends are substantively. We can very well use emotional strategies to maximize our desired ends, or are rational in trying to maximize emotionally charged values. In fact, Max Weber's (1978) notion of value rationality captures this process, and research in the sociology of emotions suggests that emotional states and emotional attachments provide motivations for many different kinds of actions (Turner and Stets 2006).

In addition, economist Robert Frank has argued that even what may seem as nonself interested behavior is, in fact, rational. In his book, Passions within Reason: The Strategic Role of Emotion (1998), Frank focuses on the intersection between emotion and economy in the so called "commitment problem." The gist of this problem is that commitment appears irrational because it is based on emotions such as love or anger. However, Frank reasons that it is in one's interest to engage in commitment often because otherwise one's position in a reference group would suffer if one did not make these commitments, which would worsen one's wellbeing in a long term. Hence, there is a calculus of rationality even in apparently irrational behavior, which Frank calls "shrewdly irrational" (Frank 1987). In this case, emotions seem to facilitate rational action because they permit us to act in ways compatible with our long term interests.

Focusing on the link between cognition and emotion, neuroscientific and psychological experimental evidence also points to the role of affect for rationality. Neuroscientist Antonio Damasio (1994) argues that affect is essential to rational action. He posits that human thought is made largely from images, i.e., symbolic and perceptual representations, and that through a life time of learning people link these images to positive or negative feelings, or what he calls somatic markers. This means that when a future outcome is considered and an acquired link between the image of this outcome and affect is positive, this is perceived as a prompt for action. On the other hand, if contemplating a future outcome triggers negative somatic markers, this

\footnotetext{
${ }^{3}$ Certainly, putting a value on happiness is rather difficult, since happiness is not as easily quantifiable as money. However, in principle the logic remains unchanged.
} 
sounds an alarm. Damasio concludes that "the effective deployment [of reasoning strategies] probably depends, to a considerable extent, on a continued ability to experience feelings" (1994: xii). Subjects in his studies who due to injuries sustained to the prefrontal and somatosensory cortices of the brain had a diminished capacity to experience emotion were severely hindered in their ability to make intelligent practical decisions.

Following this research, Slovic et al. (2004) argue that affect can serve as a heuristic for rational decision making: "Using an overall, readily available affective impression can be easier and more efficient than weighing the pros and cons of various reasons or retrieving relevant examples from memory, especially when the required judgment or decision is complex or mental resources are limited" (p. 314). Hence, to make decision-making easier, people base their judgments of an activity or an object not only on what they think about it but also on how they feel about it (Alhakami and Slovic 1994). Using emotions as a heuristic may be also one of the reasons why people engage in transactions with those they already know. As exchange theory stipulates, commitment reduces negative emotions like apprehension and anxiety associated with uncertainty, and hence lowers the emotional costs to the exchange, thereby increasing overall payoffs (Kollock 1994).

But while heuristics are often used to solve problems more efficiently, they also lead to significant departures from what synoptic rationality would yield (Kahneman et al. 1982). Affect can serve as a shortcut, but it can often also mislead, i.e., lead people to make suboptimal decisions. For instance, studying the relationship between affect and perceptions of risk, Finuncane et al. (2000) conducted an experiment and found that in situations of equal benefits, when information stated that benefit was high, this led to more positive affect, and hence the interpretation that risks are low. On the contrary, negative affect led to inference about low benefits. In another study in the area of finance, Ganzach (2000) found that if unfamiliar stocks were perceived as good based on the global attitude, they were judged to have high return and low risk, which may have not been actually the case. Likewise, Hsee and Kunreuther (2000) found that people were willing to pay twice as much to insure a beloved antique clock (that no longer works and cannot be repaired) against loss in shipment to a new city than to insure a similar clock for which one holds no special feelings. It is important to note that in both cases, the insurance would pay $\$ 100$ in the event of loss. Hence, for all practical purposes, paying extra money for the insurance of a beloved clock was an irrational decision.

Furthermore, some experimental evidence shows that, in spite of the availability of information needed to make a decision based on analytical reasoning, people resort to making a decision based on their feelings. Denes-Raj and Epstein (1994) showed that, when offered a chance to win $\$ 1$ by drawing a red jelly bean from an urn full of jellies of many different colors, individuals often elected to draw from a bowl containing a greater absolute number, but a smaller proportion, of red beans, (e.g., seven in 100) than from a bowl containing fewer red beans but a better probability of "red bean selection" (e.g., one in ten). These individuals would say that even when they knew that the probabilities were against them, they felt they had a better chance when there were more red beans. Overall, these experiments point to the downside of affect as a heuristic. Like other heuristics, affect can help us make 
decisions easier, but it can also lead to courses of action that are suboptimal in terms of efficiency.

Although neuroscientists and psychologists emphasize the link between cognition and affect, and view affect as a rational decision-making heuristic because of limited cognitive abilities of individuals, sociologists emphasize that people revert to emotions also because of uncertainty that derives from sources other than cognition. These include uncertainty due to the changes in the external environment and the social nature of economic interactions, which both create conditions of true, immeasurable, uncertainty conceptualized by Frank Knight (2002). True uncertainty, often referred to as Knightian uncertainty, characterizes conditions where the variance of the probability distribution is itself unknown and hence risk cannot be estimated (Beckert 1996). According to DiMaggio (2002: 80), in the "conditions of Knightian uncertainty, when economic actors with rational intentions have little basis for estimating risk," they revert to what John Maynard Keynes's (1936) called "animal spirits," i.e. "emotional feeling states that shape economic behavior above and beyond what a purely cognitive, rational model might lead one to expect" (DiMaggio 2002: 79).

If market actors had superior cognitive capacities and perfect information, were acting in stable environments, and their decision making were not interdependent, then there would be no uncertainty, and hence no need to fall back on emotions to guide economic actions. Actions would be simply based on known and certain economic conditions. However, none of the above conditions obtains. In particular, sociologists point out the complexity of decision making because of the social nature of economic situations. This means, as DiMaggio points out, that "to form rational expectations, each decisionmaker must take into account the decisions that all others are likely going to make" (2002: 85). Because actions are interdependent, market actors are not only uncertain about the future states of the world, but they are also uncertain about the other market actors' beliefs about the future states of the world, that is, the socially constructed expectations about the future. These expectations will be related to sentiments, feelings of confidence (or doubt) in market activity that will shape actors' economic decisions.

The notion that economic decision-makers take into account decisions of others in formulating their preferences underscores the relational nature of economic exchanges. But actors do not only take others into account prior to their action process (to shape their preferences). In fact, most economic transactions are processes that involve some form of interaction, virtual or face-to-face. This interactional dimension of transactions generates emotional responses that shape eventual economic outcomes because they can break-down the given means-ends procedural logic of rationality. That is, emotions do not only serve as a heuristic for rational decision making but they also induce economic action types other than the generally assumed rational action. I turn to this point in the second part of the paper.

\section{Emotional embeddedness: Focus on interactions}

The literature reviewed in the first part of this article focuses on how emotions matter for individual action outside of the interactional context, such as for 
occupational role performance (emotion management research), job performance (emotional intelligence research) and rational decision making (affect-as-a-heuristic research). Instead of this individualistic focus, I want to direct our attention to why and how emotions matter in economic interactions, and explicate this aspect of the emotional embeddedness of economic processes.

Mark Granovetter famously asserted that "the behavior and institutions [of economic life] are so constrained by ongoing social relations that to construe them as independent is a grievous misunderstanding" (1985: 481-482). This statement about the embeddedness of economic action in social networks became the basis of expansive research in economic sociology (for a review see Smelser and Swedberg 2005). Analogously, I propose a concept of emotional embeddedness of economic action, arguing that because economic action is interdependent and because transactions between parties to an exchange are always relational, emotions produced in interaction significantly influence economic outcomes. Like culture, networks, institutions, and power, emotions also enable and constrain economic activity.

This relational view of the role of emotions in economic processes builds on interactionist theories of emotions (for review, see Turner and Stets 2006). One of the key contemporary contributors to this perspective is Randall Collins (1981, 2004) who follows Goffman (1967) and Durkheim (1965[1912]) to focus on interaction rituals as the micro basis of social structure. Interaction rituals have a strong emotional component; they generate emotional energy. According to Collins, individuals always strive to maximize emotional energy in their encounters, and this is mediated by power and status. Another strand of interactionism builds on the symbolic interactionism of Mead (1934, 1938) and Cooley (1964 [1902]) and focuses more on the self and identity as the catalysts of emotional arousal in interaction situations. From this perspective, which is also informed by the Gestalt philosophy, positive emotions are generated when one's view of one's self is confirmed by others in interactions (Turner and Stets 2006). Individuals pursue various strategies to achieve this congruence and consistency.

Although the interaction ritual and the symbolic interactionist approaches differ in their emphases, they both share a premise that any encounter has underlying, more or less intense, emotional currents. If we apply this line of thinking to the economic realm, we can assume that encounters related to production, consumption, distribution or exchange of goods and services will involve economic actors who will either build or not positive affect during the process of transacting, and this will have consequences for economic outcomes.

Consider, for instance, a very typical economic transaction in today's global world, foreign direct investment, where actors from two different countries come together to negotiate a foreign investment effort, such as taking over (a part of) an established firm in the host country. Here, an economic transaction can be likened to a social interaction that will lead to a formation of a relationship. Doing just the opposite of Gary Becker (who interpreted all social actions through the lens of utility maximizing), let us interpret a supposedly rational economic process through a social lens. Let us consider closing an investment deal as similar to getting married. Whether the marriage will happen or not does not only depend on the partners' objective evaluation of costs and benefits of this transaction. First off, calculating 
transaction costs is pretty difficult. The two potential partners may be able to say precisely how much each has on their bank accounts, but how do they evaluate their ability to communicate successfully, or their extent of flexibility in adopting to a newjoint-living arrangement? Even if they are able to do just fine on their own, can they extrapolate from this their ability to live together? And even if one of the parties has had previous marriage experience (i.e., one company has formed partnerships with companies in other countries), can this experience really be a sound basis for the assessment of a life with a partner from a different background, different national origin, with different economic habits?

In case of marriage, at least in the contemporary West, much of this uncertainty would be overcome during the courtship period, when through a series of interactions, the two potential partners would form impressions of one another. If there were no uncertainty, and the two knew ahead of time that their relationship will work out to the benefit of both involved, there would be no need for a series of interactions before "closing the deal." However, this is not the case and is the reason why formation and affirmation of emotions plays a crucial role. Ultimately, the two prospective partners build sympathy and continue to like, love, each other, or they do not and eventually go their separate ways.

Since economic actions are social actions (Weber 1978), we have no reason to believe that on some level, economic transactions and negotiations of economic deals with happen differently. In fact, DiMaggio (1993: 126-127) emphasized that under conditions of uncertainty, economic agents are "thrown back on sympathy as an assessment criterion.... Sympathy is constructed in part out of categories (like us/ not like us) and in part out of ongoing interactions in which participants form strong impressions (confidence, distrust)." And ultimately, if sympathy is built so that both parties understand this economic transaction as "cooperation and collaboration," "partnership" or a "joint-venture," this may have quite a different effect on closing a potential foreign investment deal than if this effort is perceived as a "hostile takeover," for instance. While we have little empirical evidence on how this works in the reality of large investment deals, experimental research does confirm that, in cases of simple negotiations, there is a positive association between positive feelings on the part of both parties to an exchange and likelihood of cooperation (Forgas 1998; McGinn and Keros 2002). Based on this we can hypothesize that building of sympathy is going to be important for economic action. Ceteris paribus, those economic exchanges where transactors will fail to build at least some basic amount of sympathy will be less likely to realize.

\section{Sympathy, trust and economic action}

According to the quote from DiMaggio above, one way sympathy will matter is because it will be strongly linked to the formation of trust, considered crucial in economic processes (Kramer 1999; Podolny and Page 1998). Jens Beckert (2005) argues that trust in markets has to be understood as an interaction between trust-giver and trust-taker, and that the trust-taker performs acts of self-presentation in order to win the trust-giver's trust. These strategies of self-presentation include a) commitment (i.e., "producing trustworthiness by erecting cognitive or normative barriers to withdrawal" [Beckert 2005: 23]), b) congruence to expectations of the 
trust-giver, often by emphasizing similarity between the two, c) signaling competence (i.e., some ability of the trust-taker that makes her worthy of trust) or d) signaling integrity or authenticity of the trust taker. While none of these mechanisms speaks directly about the importance of positive emotions, it is easy to infer that all of the four self-presentation strategies identified by Beckert entail emotion (not only impression) management by the trust-taker and, in turn, generate some emotional responses in the trust-giver. In addition, the mere notions of commitment, congruence to expectations, competence, and integrity all have positive connotations and they are ranked high in our contemporary Western value space, so their manifestations would help build positive affect.

In a different account of trust, following Simmel, Luhmann, and Giddens, a business scholar Guido Moellering (2001, 2006) emphasizes that trust entails suspension (2001: 414). Trust "presumes a leap to commitment, a quality of 'faith' which is irreducible" (Giddens 1991: 19). Giddens (1990) argues that the ability to trust is learned in infancy through the ambivalent experience of love from caretakers on the one hand, and the contemporary absence of caretakers on the other, whereby infants have to develop the ability to reach a state of trust, which "brackets distance in time and space and so blocks off existential anxieties" (1990: 97). This is akin to solving the trust/mistrust problem identified as a successful conclusion of the first phase of development by Erik Erikson (1950). Based on this social-psychological explanation, we can infer that suspension necessary for a trust relationship, or the leap of faith that is beyond calculus, is grounded in basic emotional states like feeling loved and feeling safe. Following this logic, one could hypothesize that leaps of faith to form trust in the life beyond infancy are enabled by positive emotional reactions that are produced and felt in the situation in which trust is to be formed. We can stipulate that in cases where positive emotions are lacking, the leap of faith does not happen and a person does not "allow" him/herself to trust. The phrase "I fear to trust" is telling. In the presence of negative emotions, like fear, the act of suspension, and consequently trust, is unachievable, even if all the information at hand, rationally processed, leads one to conclude that one has every reason to trust. If one does not also have "all the feelings necessary to do so" trust will not realize.

For instance, in my research on foreign investment, I found that positive feelings were one of the decisive factors in the formation of trusting relationships that led to the realization of foreign investment attempts. In cases where negative feelings prevailed, the transactions were less likely completed as planned. In one case, middle management and workers of an East European firm mobilized against an acquisition attempt by an American corporation, which objectively looked very attractive for the targeted firm as it would increase their market share and eliminate the key competitor from the market. Explaining the situation, one of the informants quipped that the Americans behaved as if, "[they] are going to eat [us] for breakfast," suggesting arrogance and a condescending attitude that offended Slovenians. In addition, the media reported on the American way of doing business, implying lack of care for workers and merciless downsizing, and framed the American attempt as "a hostile takeover." These labels and interpretations represented obstacles to developing trust between the two transaction partners. In no small way, negative feelings may have fueled the opposition to the American investment, which in combination with other negative conditions eventually propelled Americans to withdraw their offer (Bandelj 2008). 
On the whole, emotions are important in economic interaction because sympathy helps build trust, which ultimately helps solve the uncertainty problem. (Obviously, as the example above indicates, the opposite also holds: antipathy leads to mistrust). Nevertheless, it would be reductionist to consider the importance of emotions simply because they are related to trust (or to even equate emotions with trust as does Pixley [1999, 2002b, 2004], for instance). It is plausible that emotions have an independent role in economic interactions. And while in practice this may be hard to distinguish, we can do so analytically. In particular, we can point to the distinction between trust as an attitude (Berezin 2005), without distinct bodily states associated with it, and emotion as a state with its physical properties. The phrase, "gut feelings" captures this nicely. Emotions come with butterflies in the stomach, or tensed muscles, or redness of face, sweaty hands, or cold feet, literally and metaphorically. I elaborate on the visceral qualities of emotions, and their consequences, in the next section.

\section{Physicality of emotions and economic interactions}

The individualistic perspectives reviewed in the first half of the article generally consider emotions as easily recognizable and manipulable. A flight attendant who manages emotions to fit the job requirements of an always smiling and cheerful service worker, or a manager who strives to develop emotional competencies to be able to guide her subordinates in a more effective way, or a financial expert, who is confident in the market, and makes stock purchase decisions based on this assessment, all these actors have to be consciously aware of their emotions to manipulate them and to use them to various ends. But as Mabel Berezin importantly points out, "the moment that one is conscious of an emotion and attempts to control it, emotion becomes a cognition and is no longer strictly speaking an emotion" (2005: 118).

Indeed, some scholars propose that emotions are first and foremost bodily states. William James (1884) defined emotions as feelings caused by changes in physiological conditions relating to the autonomic and motor functions. When we perceive that we are in danger, for example, this perception sets off a collection of bodily responses, and our awareness of these responses is what constitutes fear. Hence, "we feel sorry because we cry, angry because we strike, afraid because we tremble, and [it is] not that we cry, strike, or tremble, because we are sorry, angry, or fearful, as the case may be" (James 1884: 190). While other scholars disagree that emotions are solely or primarily physiological responses, the fact that emotions have physical manifestations is widely accepted (Berezin 2005).

Jean-Pierre Hassoun (2005: 103-104) captures this physical quality of emotions as they play out in the economic arena par excellence, a stock market trading floor:

[A]nyone who has directly observed financial market actors knows that emotions and their verbal and physical expression are a daily part of these activities.... Financial market actors' behavior openly expresses such varied emotions as sympathy, admiration, anger, aggressiveness, feelings of rivalry, shame, and humiliation.... [Emotions] can be read first of all on faces, where strong tension and concentration may be perceived, but also at those moments when facial muscles, and the body with them, suddenly go loose.... 
[Emotions] are on daily display in the form of angry verbal outbursts, shoving, friendly, ambiguous, or aggressive backslapping, complicitous hand taps, hateful or empathetic looks, yelling, swearing, and insults.

Based on Hochschild's concept of emotion work, we can interpret such market behavior as management of emotions appropriate to a particular role of a financial trader defined by the trading floor culture (see also Abolafia 1996). However, it is important to note that not all emotional expressions can be controlled, and hence strategic in helping a trader be as successful as possible in his or her job. In particular, those emotions that show in non-verbal physical signals, e.g., sweating, skin redness, diverting gaze, or shaking voice, may be rather subconscious.

The physical component of emotions is interesting precisely because it represents the non-cognitive part of emotions and thus cannot be easily subsumed into the rational action framework. Different situations call forth different emotive states that are not only consciously manufactured but are immediately felt, perceived and experienced, and thus hard to articulate. These "on the spot" feelings can be related to what many economic actors refer to as intuition (Agor 1986; Abolafia 1996). Intuition may be precisely the state that combines immediate cognition and emotional "gut" reaction in influencing behavior. Especially because they cannot be completely mastered by cognition and hence controlled, visceral reactions, gut feelings, and states that are more or less subconsciously experienced may interfere with rationality.

Indeed, if affect and thought are as intimately intertwined as Damasio (1994, 1999) suggests, then any interpretation of information that one considers relevant for an economic transaction will conger up some physically experienced feelings, not only thoughts and attitudes. Hence, interpreting a potential's partner social characteristics (position in a network, reputation, social identities) leads to feeling formation, in addition to cognitive evaluation. Together with other impressions, these feelings become a part of economic transactions and negotiations, and can shape their outcome. Moreover, it is unlikely that as the relationship proceeds, i.e., during the process of economic interaction with many encounters following one another, that feelings are going to stay unchanged. In the interaction process, people constantly pick up clues that produce new emotional states that either affirm existing ones or are quite different from them. In addition, a person engaged in the interaction also perceives the emotional states of interaction partners, which in turn influence one's own emotions. Hence, these "interaction-generated" physically experienced emotional states can also induce a person to change his or her preference orderings or even to change his or her preference set, which would result-during the economic interaction - in setting new goals and new strategies to reach them, more in line with the new emotional states. As a consequence, the means-ends logic of decision making, which by definition of rational action is set before the transaction occurs, may not be retained throughout the interaction process. Hence, utility maximization is unlikely to realize.

It is important to note that the influence of emotions in interaction should not be conceived as random mood swings, or changing one's mind on a whim. True, interaction is always somewhat uncertain and ambiguous and can be interpreted in different ways. Nevertheless, this does not render interaction completely unpredict- 
able and arbitrary. While people receive new information and perceive new emotions during the interaction itself, they are able to use these as social and emotional clues that they know how to interpret. Perception and interpretation of these social clues can be linked to that person's past experience and to connections stored in memory (Damasio 1999). People will be positively oriented if the interaction generated clues are going to affirm their own social identity, align with things they themselves consider valuable, and produce cultural matching. This will generate positive affect. On the other hand, when encountering behavior and attitudes dissonant to their experiences, upbringing, cultural tastes, in short habitus (Bourdieu 1980), people will tend to dislike those displaying such behavior, perhaps so much as to refrain from further interaction with them. Because these interaction-induced sensations/ impressions work on the non-cognitive level, we can suspect that people will not be able to justify well their decisions to refrain from or continue interactions with particular partners, except to say that they had "a bad feeling" about the exchange or, alternatively, that they "simply like" their potential partner.

\section{Emotional embeddedness and rationality of economic actions}

From the above discussion, we can conclude that the emotional embeddedness of economic action has important consequences for the common understanding of economic behavior as rational action. According to neoclassical theories, rational actors follow a means-ends approach and make decisions deductively by first determining their goals (ends), then evaluating the potential strategies (means) to reach goals based on the information at hand and, finally, choosing the alternative that leads to profit maximization. Researchers now readily acknowledge that possession of perfect information is impossible and that actors have cognitive limitations that prevent them from maximization. Rather, as Herbert Simon (1957) theorized, actors are bounded-rational and they satisfice rather than maximize. Also, it is recognized now that economic actors may choose to maximize goals other than profits. Nevertheless, what is characteristically assumed of rational economic action is its procedural means-ends logic, whereby goals and preferences are set a priori and are stable over the course of action.

What implications, then, does emotional embeddedness have for such means-ends rational action? As we reviewed, some clearly argue that emotions enable rational economic action because they shape the preference formation and help actors overcome uncertainty. However, emotions may also constrain rationality because a) heuristics, including affect, often lead actors to decide on courses of action that are suboptimal with regards to rationality, 2) non-cognitive aspects of emotions that accompany economic interactions may break down the consistent means-ends schema. Considering these conditions, it may be more analytically useful to conceptualize economic action as practical rather than as rational.

Practical action

Practical action refers to activity whereby reasoning is infused with unreflective routine following, emotional reactions, normative commitments, and creativity. 
Practice is not wholly consciously organized (Bourdieu 1980). It is not random or purely accidental but, as one thing follows from another, practical action happens. Bourdieu uses the metaphor of social life as a game to exemplify the relationship between the determined and the improvisational aspects of practice. First, all games have rules and they determine what players can and cannot do. Second, games are learned through explicit teaching as well as experientially, in practice. Accordingly, when they are engaged in social practices, most people depend on their social competence, their own experience, or their practical sense of logic rather than an analytical model.

The theory of practical action is grounded in ethnomethodology, the work of Harold Garfinkel in particular, and emphasizes the role of routines, conventions, and "practical reason" in guiding action. As Garfinkel observed, actors in everyday life are practical and largely follow routines. Hence, if the sphere of economic life and business is just another realm of social life, preeminence of the rational action model to capture economic processes may be unwarranted. In addition, practical action is characterized by the fact that the affective and evaluative dimensions of action are intimately bound up with cognition (DiMaggio and Powell 1991: 22).

The practical action model also builds on the philosophy of pragmatism and a view that action is not just contingent on the situation but that the "situation is constitutive of action" (Joas 1996: 160, emphasis added):

In order to be able to act, the actor must pass judgment on the nature of the situation. Every habit of action and every rule of action contain assumptions about the type of situations in which it is appropriate to proceed according to the particular habit or rule. In general, our perception of situations already incorporates a judgment on the appropriateness of certain kinds of action. This explains why situations are not merely a neutral field of activity for intentions, which were conceived outside of that situation, but appear to call forth, to provoke certain actions already in our perception (Joas 1996: 160).

Action, then, is not merely teleological, i.e., geared toward specific identified ends, teloi, but is creative. Activity itself is a source of ends. Goals and preferences do not simply derive from the "inside" of actors but also depend on situations in which these actors find themselves and creative solutions they identify in response to novel circumstances (Whitford 2002: 340). Joas's notion of creative rather than teleological action uncovers the potential ambiguity in the relationship between means and ends. Rational action presupposes that the relationship between means and ends is clearly defined in a means-ends schema: i.e., that goals (ends) are known ex ante, and that on the basis of these ends, the most optimal strategy (or means) is identified, which will allow an actor to accomplish his or her goals best. However, in actual situations, especially in conditions of high uncertainty and emotional embeddedness, people often cannot know in advance what the consequences of their actions will be, so an optimizing strategy cannot be identified. Moreover, if situations themselves are constitutive of action, then it is possible that the goals and strategies of action (i.e., both ends and means) are modified during the process of action itself. In certain cases, both ends and means emerge out of the situation and are not given prior to it, as assumed by rational action. This suggests that business actors engage not merely in procedural rationality, i.e., means-end calculations, but 
in other types of action, whereby ends and means are not clearly identified prior to the action process nor they necessarily remain stable during this process. I identify two types of such creative action below: situational adaptation and improvisation.

Situational adaptation and improvisation

Based on the above discussion, I propose that economic behavior exemplifies multiple action principles. Certainly, one of these principles is rational instrumental action, which is characterized by a clear means-ends logic: ends are defined ex ante, means are known and selected by optimization, that is, by weighing which means will best help the actor achieve the desired ends for the least amount of effort or cost.

However, when the means-ends logic breaks down because of uncertainty and consequent social and emotional embeddedness of economic processes, other types of action are common. First of all, there are circumstances where ends and means change during the process of action itself. John starts with a particular goal in mind and with a selected strategy that seems optimal. However, because of the openended, contingent character of economic interactions, which conjures up emotions in interaction, unexpected a priori, John feels compelled to change these goals or reshuffle the strategies as the process of action evolves. We can call this type of action situational adaptation due to contingency.

The second case of economic action where a rational means-ends logic does not exist, is the case of severe uncertainty where ends are unclear, and a stable ordering of means/ preferences is absent as well. In this case, the action is best characterized by improvisation, where action and cognition occur simultaneously. That is, composition and execution converge in time (Moorman and Miner 1998). By immersion into the action process itself, John discovers ends and means as he goes along, "on the fly," as emotionally charged situations themselves bring forth the acts (Joas 1996). The guiding principle for such creative action is a feeling for the situation rather than the full comprehension and command of a situation (Bourdieu 1980). In some cases, improvisation results in innovation, also a type of creative action, in which the goals are not in sight nor are the means, and it is the innovation process itself that helps an actor articulate them (Beckert 2003). This may be particularly the case for entrepreneurs, who often say that they listened to their heart, or followed intuition, or trusted their gut feelings, when they pursued an idea. As we know, sometimes these ideas work out and sometimes (most of the times?) they don't. Studying this variation can be a fruitful research site for investigating emotional embeddedness.

If multiple economic action principles exist, sociologists are well equipped to study when, i.e., under what conditions, some action principles are more likely to occur that others. An adequate treatment of this question would require more empirical research but we can stipulate that whether economic actors are more or less engaged in means-ends calculations to satisfy their goals (i.e., instrumental rationality) will depend on: ${ }^{4}$

a) goals of action: how clearly they are defined a priori and how stable they are during the process of decision making,

\footnotetext{
${ }^{4}$ In this discussion we should keep in mind that synoptic rationality is impossible and even if actors engage in consistent and internally coherent means-ends calculation, they have limited cognitive abilities and can be only bounded rational (Simon 1957; Kahneman 1994).
} 
b) means to reach goals: how uncertain they are a priori and how stable they are during the process of decision making,

c) participation of actors involved: how unitary they are, how many parties are involved, how clear it is who can make decisions, and what the decision makers' preferred ways are of handling situations,

d) time constraints: how quickly decisions need to be made, what is their perceived urgency, and how much time can decision makers devote to them, ${ }^{5}$ and

e) additional uncertainty: how turbulent and unpredictable environments are that contribute to uncertainty beyond that generated by the factors mentioned above.

\section{Conclusion}

Although scholars have paid some attention to emotions in the economy, I argued here that their treatment has been incomplete because they almost exclusively focused on the individuals' preferences and behaviors, as elaborated in the work on emotion management, emotional intelligence, and emotions as a heuristic. In contrast to these individualistic approaches, I focused on the relational and interactional nature of economic processes and offered an initial elaboration of the emotional embeddedness concept. I argued that emotions - in their cognitive but also non-cognitive, physical form-structure economic action; not only do they shape preference formation or performance of economic roles (as others have shown), emotions also influence economic processes because they are generated during the interaction process and cannot be completely anticipated nor controlled. This is because of emotions' visceral qualities but also due to a need to interpret, understand, and evaluate partners during the interaction; the process in which economic actors build sympathy or antipathy. Interaction-induced emotions influence the stability of preferences as the interaction process is ongoing and therefore render action principles other than means-ends rationality. As a consequence, economic activities may often resemble more closely creative action, i.e., situational adaptation and improvisation, rather than rational (means-ends) decision-making. Improvisation characterizes situations where ends (goals) and means are unclear at the beginning of a transaction process and get articulated as a consequence of emotional embeddedness experienced during a process. Situational adaptation characterizes situations in which means or ends of action change because of interactioninduced emotions that prompt actors to choose new means or ends.

That economic action is often creative is scarcely recognized. Unjustly so. After all, economic action is social action, and we have good reasons - and feelings - to believe that all those factors that matter for other social relationships, including emotional embeddedness, will matter also for economic transactions. The challenge for future research is to find empirical sites to test and to provide further explication of the role of emotions in creative economic interactions.

\footnotetext{
${ }^{5}$ As Moorman and Miner (1998) find, improvisation is the degree to which composition and execution converge in time. This implies that with little time, when decisions are made quickly or even on the spot, improvisation as the principle of action is more common.
} 
Acknowledgments A previous version of the article was presented at the American Sociological Association Meetings, Montreal, August 11-14, 2006. I thank Viviana Zelizer, Mabel Berezin, and an anonymous reviewer for their helpful comments

Open Access This article is distributed under the terms of the Creative Commons Attribution Noncommercial License which permits any noncommercial use, distribution, and reproduction in any medium, provided the original author(s) and source are credited.

\section{References}

Abolafia, M. (1996). Making markets: Opportunism and restraint on wall street. Cambridge: Harvard University Press.

Agor, W. H. (1986). The logic of intuitive decision making. New York: Quorum Books.

Alhakami, A. S., \& Slovic, P. (1994). A psychological study of the inverse relationship between perceived risk and perceived benefit. Risk Analysis, 14(6), 1085-1096.

Bandelj, N. (2008). From communists to foreign capitalists: The social foundations of foreign direct investment in postsocialist Europe. Princeton, NJ: Princeton University Press.

Bar-On, R., \& Parker, J. D. A. (2000). Handbook of emotional intelligence. San Francisco: Jossey-Bass.

Beckert, J. (1996). Uncertainty and the embeddedness of economic action. Theory and Society, 25(6), $803-840$.

Beckert, J. (2003). Economic sociology and embeddedness. How shall we conceptualize economic action? Journal of Economic Issues, 37, 769-787.

Beckert, Jens. (2005). Trust and the performative construction of markets. MPIfG Discussion Paper 05/8. Cologne: Max Planck Institute for the Study of Society.

Berezin, M. (2005). Emotions and the economy. In N. Smelser \& R. Swedberg (Eds.), The handbook of economic sociology (2nd ed.), pp. 109-130. Princeton, NJ: Princeton University Press.

Bolton, S., \& Boyd, C. (2003). Trolley dolly or skilled emotion manager? moving on from Hochschild's managed heart. Work, Employment and Society, 17(2), 289-308.

Bourdieu, P. (1980). The logic of practice. Stanford: Stanford University Press.

Boyatzis, R. E., Cowan, S. S., \& Kolb, D. A. (1995). Innovations in professional education: Steps on a journey to learning. San Francisco: Jossey-Bass.

Cherniss, C. (2000). Emotional intelligence: What it is and why it matters. Paper presented at the annual meeting of the society for industrial and organizational psychology, New Orleans, April 15, 2000.

Collins, R. (1981). On microfoundations of macrosociology. American Journal of Sociology, 86(5), 9841014.

Collins, R. (2004). Interaction ritual chains. Princeton, NJ: Princeton University Press.

Cooley, C. H. (1964). Human nature and the social order. New York: Schocken Books. Originally published in 1902 .

Damasio, A. (1994). Descartes' error: Emotion, reason, and the human brain. New York: Harper Collins.

Damasio, A. (1999). The feeling of what happens: Body and emotion in the making of consciousness. New York: Harcourt Brace and Co.

Denes-Raj, V., \& Epstein, S. (1994). Conflict between intuitive and rational processing: When people behave against their better judgment. Journal of Personality and Social Psychology, 66, 819-829.

DiMaggio, P. (1993). Nadel's Paradox revisited: Relational and cultural aspects of organizational structures. In N. Nohria \& R. Eccles (Eds.), Networks and organization, pp. 118-142. Boston: Harvard Business School Press.

DiMaggio, P. (2002). Endogenizing 'animal spirits': Toward a sociology of collective response to uncertainty and risk. In M. F. Guillen, R. Collins, P. England \& M. Meyer (Eds.), The new economic sociology: Developments in an emerging field, pp. 79-100. New York: Russell Sage Foundation.

DiMaggio, P., \& Powell, W. (1991). Introduction. In W. Powell \& P. DiMaggio (Eds.), The new institutionalism in organizational analysis, pp. 1-40. Chicago: University of Chicago Press.

Durkheim, Emile. (1965). The elementary forms of religious life. New York: Free Press. [1912].

Elster, J. (1998). Emotions and economic theory. Journal of Economic Literature, 36, 47-74.

Erikson, E. (1950). Childhood and society. New York: WW Norton.

Fineman, S. (1993). Emotions in organizations. London: Sage.

Finucane, M., Alhakami, A., Slovic, P., \& Johnson, S. M. (2000). The affect heuristic in judgments of risks and benefits. Journal of Behavioral Decision Making, 13, 1-17. 
Forgas, J. (1998). On feeling good and getting your way: Mood effects on negotiating strategies and outcomes. Journal of Personality and Social Psychology, 74, 565-577.

Frank, R. (1987). Shrewdly Irrational. Sociological Forum, 2(1), 21-41.

Frank, R. (1998). Passions within reason: The strategic role of emotions. New York: WW Norton and Company.

Ganzach, Y. (2000). Judging risk and return of financial assets. Organizational Behavior and Human Decision Processes, 83, 353-370.

Giddens, A. (1990). The consequences of modernity. Stanford: Stanford University Press.

Giddens, A. (1991). Modernity and self-identity. Cambridge: Polity Press.

Goffman, E. (1967). Interaction ritual. New York: Doubleday.

Granovetter, M. (1985). Economic action and social structure: The problem of embeddedness. American Journal of Sociology, 91, 481-510.

Harding, J., \& Pribram, E. D. (2004). Losing our cool? following Williams and Grossberg on emotions. Cultural Studies, 18(6), 863-993.

Hassoun, J.-P. (2005). Emotions on the trading floor: Social and symbolic expressions. In K. K. Cetina \& A. Preda (Eds.), The sociology of financial markets, pp. 102-120. Oxford: Oxford University Press.

Hochschild, A. R. (1979). Emotion work, feeling rules, and social structure. American Journal of Sociology, 85(3), 551-575.

Hochschild, A. R. (1983). The managed heart: Commercialization of human feeling. Berkeley: University of California Press.

Hsee, C. K., \& Kunreuther, H. C. (2000). The affection effect in insurance decisions. Journal of Risk and Uncertainty, 20, 141-159.

Hunter, J., \& Hunter, R. (1984). Validity and utility of alternative predictors of job performance. Psychological Bulletin, 76(1), 72-93.

James, W. (1884). What is an emotion? Mind, 19, 188-204.

Joas, H. (1996). The creativity of action. Cambridge: Polity Press.

Kahneman, D. (1994). New challenges to the rationality assumption. Journal of Institutional and Theoretical Economics, 150, 18-36.

Kahneman, D., Slovic, P., \& Tversky, A. (1982). Judgment under uncertainty: Heuristics and biases. New York: Cambridge University Press.

Keynes, J. M. (1936). General theory of employment, interest, and money. New York: Harcourt Brace.

Knight, F. (2002). Risk, uncertainty and profit. Washington, D.C.: Beard Books.

Kollock, P. (1994). The emergence of exchange structures: An experimental study of uncertainty, commitment, and trust. American Journal of Sociology, 100, 313-345.

Kramer, R. (1999). Trust and distrust in organizations: Emerging perspectives, enduring questions. Annual Review of Psychology, 50, 569-598.

Matthews, G., \& Wells, A. W. (1994). Attention and emotion: A clinical perspective. Hillsdale, NJ: Lawrence Erlbaum.

McGinn, K. L., \& Keros, A. T. (2002). Improvisation and the logic of exchange in socially embedded transactions. Administrative Science Quarterly, 47, 442-473.

Mead, G. H. (1934). Mind, self and society. Chicago: University of Chicago Press.

Mead, G. H. (1938). The Philosophy of the Act. Chicago: University of Chicago Press.

Moellering, G. (2001). The nature of trust: From Georg Simmel to a theory of expectation, interpretation and suspension. Sociology, 35(2), 403-420.

Moellering, G. (2006). Trust: Reason, routine, reflexivity. Oxford: Elsevier.

Moorman, C., \& Miner, A. S. (1998). Organizational improvisation and organizational memory. Academy of Management Review, 23(4), 698-723.

Peter, S., \& Mayer, J. (1990). Emotional intelligence. Imagination, Cognition and Personality, 9(3), $185-211$.

Pierce, J. L. (1996). Gender Trials: Emotional Lives in Contemporary Law Firms. Berkeley: University of California Press.

Pixley, J. (1999). Beyond twin deficits: Emotions of the future in the organizations of money. American Journal of Economics and Sociology, 58(4), 1091-1118.

Pixley, J. (2002a). Emotions and Economics. In J. Barbalet (Ed.), Emotions and Sociology, pp. 69-89. Oxford: Basil Blackwell.

Pixley, J. (2002b). Finance organizations, decisions, and emotions. British Journal of Sociology, 53(1), 41-65.

Pixley, J. (2004). Emotions in Finance. Cambridge: Cambridge University Press.

Podolny, J., \& Page, K. (1998). Network forms of organization. Annual Review of Sociology, 24, 57-76.

Simon, H. (1957). Administrative Behavior. New York: Macmillan. 
Slovic, P., Finucane, M., Peters, E., \& MacGregor, D. (2004). Risk as analysis and risk as feelings: some thoughts about affect, reason, risk and rationality. Risk Analysis, 24(2), 311-322.

Smelser, N., \& Swedberg, R. (2005). The handbook of economic sociology (secondth ed.). Princeton, NJ: Princeton University Press.

Snarley, J., \& Vaillant, G. (1985). How lower- and working-class youth become middle-class adults: The association between ego defense mechanisms and upward social mobility. Child Development, 56(4), 899-910.

Sternberg, R. (1995). Successful intelligence. New York: Simon and Schuster.

Turner, J. H., \& Stets, J. E. (2006). Sociological theories of human emotions. Annual Review of Sociology, 32, 25-52.

Weber, M. (1978). Economy and society. Berkeley and Los Angeles: University of California Press.

Whitford, J. (2002). Pragmatism and the untenable dualism of means and ends: Why rational choice theory does not deserve paradigmatic privilege. Theory and Society, 31(3), 325-363.

Zelizer, V. (2000). The purchase of intimacy. Law and Social Inquiry, 25, 817-848.

Zelizer, V. (2003). Intimate Transactions. In M. Guillen, R. Collins, P. England \& M. Meyer (Eds.), The new economic sociology: Developments in an emerging field, pp. 274-302. NY: Russell Sage Foundation.

Zelizer, V. (2005). The purchase of intimacy. Princeton, NJ: Princeton University Press.

Nina Bandelj is Assistant Professor of Sociology and Faculty Associate at the Center for the Study of Democracy, University of California, Irvine. Her research in economic sociology, social change, and culture has been published in Social Forces, Current Sociology, Sociological Forum, and East European Politics and Societies, among others. She is the author of From Communists to Foreign Capitalists: The Social Foundations of Foreign Direct Investment in Postsocialist Europe (Princeton University Press, 2008) and currently editing Economic Sociology of Work (Emerald Publishing, 2009). 